EGU21-13474

https://doi.org/10.5194/egusphere-egu21-13474

EGU General Assembly 2021

(c) Author(s) 2021. This work is distributed under

the Creative Commons Attribution 4.0 License.

\title{
Regional-scale susceptibility modelling of shallow landslides involving the weathered and fractured sub-surface bedrock
}

\author{
Enrico D'Addario ${ }^{1}$, Leonardo Disperati ${ }^{1}$, Josè Luis Zezerè ${ }^{2}$, Raquel Melo ${ }^{2}$, and Sergio Cruz Oliveira ${ }^{2}$ \\ ${ }^{1}$ Dipartimento di scienze Fisiche, delle Terra e dell'Ambiente, Università di Siena, Italy (enrico.daddario@unisi.it) \\ ${ }^{2}$ IGOT, Instituto de Geografia e Ordenamento do Território, Universidade of Lisboa, Portugal
}

Landsliding is a complex phenomenon and its modelling aimed at predicting where the processes are most likely to occur is a tricky issue to be performed. Apart the chosen modelling approach, for both data-driven and physically-based models, paying adequate attention to the predisposing and triggering factors, as well as the input parameters is no less important. Generally, shallow landslides mobilize relatively small volumes of material sliding along a nearly planar rupture surface which is assumed to be roughly parallel to the ground surface. In the literature it is also widely accepted that shallow landslides involve only unconsolidated slope deposits (i.e., the colluvium), then the rupture surface corresponds to the discontinuity between the bedrock and the overlying loose soil. In this work, based on systematic field observations, we highlight that shallow landslides often involve also portions of the sub-surface bedrock showing different levels of weathering and fracturing. Then, we show that the engineering geological properties of slope deposits, as well as those related to the underlying bedrock, must be considered to obtain more reliable shallow landslides susceptibility assessment. As a first task, a multi-temporal shallow landslide inventory was built by photointerpretation of aerial orthoimages. Then, a new fieldworkbased method is proposed and implemented to acquire, process and spatialize the engineering geological properties of both slope deposits and bedrock. To support the regional scale approach, field observations were collected within, in the neighbour and far from the shallow landslide areas. Finally, both physically-based and data-driven methods were implemented to assess and compare shallow landslide susceptibility at regional scale, as well as to analyse the role of spatial distribution of rock mass quality for shallow slope failure development. The results highlight that, according to geology, structural setting and morphometric conditions, bedrock properties spatially change, defining clusters influencing both the distribution and characters of shallow landslides. As a consequence, the physically-based modelling provides better prediction accuracy when two possible rupture surfaces are analysed, the shallower one located at the slope deposit / bedrock discontinuity, and the deeper one located at the bottom of the fractured and weathered bedrock horizon. Even though the physically-based and data-driven models provide similar results in terms of ROC curves, the resulting susceptibility maps highlight quite substantial differences. 